\title{
Cerebral Fractional Oxygen Extraction in Very Low Birth Weight Infants Is High When There Is Low Left Ventricular Output and Hypocarbia but Is Unaffected by Hypotension
}

\author{
CHRISTOPHER M. KISSACK, ROSALINE GARR, STEPHEN P. WARDLE, AND \\ A. MICHAEL WEINDLING \\ Department of Child Health, University of Liverpool, Neonatal Unit, Liverpool Women's Hospital, \\ Liverpool, L8 7SS, United Kingdom [C.M.K., R.G., A.M.W.], Neonatal Unit, Queen's Medical Centre, \\ University Hospital, Nottingham HG7 2UH, United Kingdom [S.P.W.]
}

\begin{abstract}
This study examined the relationships between cerebral fractional oxygen extraction (FOE), mean arterial blood pressure (MABP), left ventricular output (LVO), blood gases, and other physiologic variables in 36 very-low-birth-weight preterm infants during the first $3 \mathrm{~d}$ after birth. There was a decrease in cerebral FOE $(p=0.008)$, and rises in LVO $(p<0.0001)$ and $\operatorname{MABP}(p=0.02)$ during the $3 \mathrm{~d}$. Between $\mathrm{d} 1$ and 2 , cerebral FOE decreased $(p=0.007)$ and LVO increased $(p<0.0001)$. There was no relationship between MABP and cerebral FOE. LVO correlated negatively with cerebral FOE on $\mathrm{d} 1(p=0.01)$, but not on $\mathrm{d} 2(p=0.07)$. On $\mathrm{d} 1$, median pressure of arterial $\mathrm{CO}_{2}$ was lower in infants with low $\mathrm{LVO}\left(<5^{\text {th }}\right.$ centile $)$ and high cerebral FOE $\left(>95^{\text {th }}\right.$ centile $)$ than in infants with low $\mathrm{LVO}\left(<5^{\text {th }}\right.$ centile) but normal cerebral FOE $\left(5^{\text {th }}-95^{\text {th }}\right.$ centile $)(p=0.03)$. These findings suggest that cerebral FOE was increased only when LVO was low and there was hypocarbia. MABP had no demonstrable effect. It is likely that increased cerebral FOE is a
\end{abstract}

\section{ABSTRACT}

normal physiologic response to maintain an adequate oxygen supply to the cerebral tissues when LVO is low and hypocarbia has caused vasoconstriction. It is possible that the cerebral hemispheres are low-priority vascular beds in the preterm infant, and that the high cerebral FOE is a result of reduced hemispheric blood flow to maintain MABP in the presence of low LVO. (Pediatr Res 55: 400-405, 2004)
Abbreviations
FOE, fractional oxygen extraction
CBF, cerebral blood flow
LVO, left ventricular output
MABP, mean arterial blood pressure
$\mathrm{PaCO}_{2}$, pressure of arterial $\mathrm{CO}_{2}$
$\mathrm{Svo}_{2}$, venous oxygen saturation
$\mathrm{SaO}_{2}$, arterial oxygen saturation
IQR, interquartile range

Acquired cerebral injury is a serious problem for infants born prematurely. The EPICure study, which examined the neurologic outcomes of infants born at 25 or fewer completed weeks of gestation, found that $49 \%$ of children had disability at a median age of 30 mo (corrected for gestation) (1). These children included $23 \%$ who met the criteria for severe disability. The two most common acquired cerebral lesions are intraventricular hemorrhage and cystic periventricular leukomalacia (2). Although both have a number of suggested etiologies, one commonly suggested factor is disturbed cerebral hemodynamics $(3,4)$. A number of studies have demonstrated that blood

Received September 25, 2002; accepted February 25, 2003.

Correspondence: C.M. Kissack, M.D., Neonatal Unit, Liverpool Women's Hospital, Crown St., Liverpool, L8 7SS, United Kingdom; e-mail: uknearinfrared@yahoo.co.uk

Funded by the NHS Research and Development Executive, the Newborn Appeal, and Action Research.

DOI: 10.1203/01.PDR.0000111288.87002.3A pressure may play an important role in the control of CBF and the pathogenesis of cerebral injury $(4,5)$. There is a widely held belief among clinicians that hypotension is an important cause of impaired organ perfusion, low CBF, insufficient cerebral oxygen delivery, and consequent cerebral injury, and considerable therapeutic effort is therefore put into maintaining blood pressure. This is in spite of several studies of the relationship between blood pressure and cerebral hemodynamics, which suggest that blood pressure may not be as important as it is currently thought to be $(6-10)$. There is, however, evidence that changes in blood gases, in particular changes in $\mathrm{PaCO}_{2}$, influence cerebral hemodynamics (11-13), with a probable link between hypocarbia and cerebral injury $(14,15)$.

Our own previous work has also failed to demonstrate any significant relationship between MABP and cerebral FOE (16). Cerebral FOE represents the ratio of oxygen consumption to delivery. As oxygen delivery decreases, FOE increases so that 
oxygen consumption remains constant, until a critical point is reached at which oxygen extraction is maximal and oxygen consumption will also decrease. This study was undertaken to investigate which physiologic variables, including blood pressure, LVO, and blood gases, influence cerebral FOE in the newborn, preterm, very-low-birth-weight neonate. The primary hypothesis was that cerebral FOE correlated with MABP over the first $3 \mathrm{~d}$ after birth in these infants. We were particularly interested in those infants with very high cerebral FOE $\left(>95^{\text {th }}\right.$ centile and presumably closest to the critical point) and examined their physiologic variables in detail.

\section{METHODS}

Subjects. Thirty-six infants were studied. All infants were delivered at $<32$ wk of gestation, and had birth weights $<1500$ g. All infants had an umbilical arterial catheter for continuous blood pressure monitoring and blood sampling, and were receiving conventional mechanical ventilation. Measurements of cerebral venous saturation and cardiac function were made within the first $12 \mathrm{~h}$ after birth (d 1), between 24 and $36 \mathrm{~h}$ of age (d 2), and between 48 and $60 \mathrm{~h}$ of age (d 3). The severity of the clinical condition of the infants was assessed using the clinical risk index for babies (CRIB) score (17). Informed consent was obtained from the parents before making any measurements. The study was approved by a Regional Paediatrics Ethics Committee.

Cerebral FOE. Cerebral $\mathrm{Svo}_{2}$ was measured with a partial jugular venous occlusion technique using near-infrared spectroscopy (Hammamatsu NIRO 500, Hamamatsu UK Ltd.,Welwyn Garden City,

Hertfordshire, U.K.) and pulse oximetry (Datex, Helsinki, Finland). The technique has been described fully and validated against invasive measurements (18). The near-infrared optodes were placed in a fronto-temporal arrangement on the head, and the inter-optode distance was measured using calipers. All inter-optode distances were between 2.5 and $4.0 \mathrm{~cm}$. Nearinfrared measurements of $\mathrm{SvO}_{2}$ were considered acceptable only if there was a preceding steady baseline for both $\mathrm{Hb}$ and oxyhemoglobin $(\mathrm{HbO})$, followed by a rise in both during the partial jugular venous compression, with both returning to the preexisting baseline immediately after the compression.

$\mathrm{SaO}_{2}$ was measured using the pulse oximeter in beat-to-beat mode, taking a reading every $0.5 \mathrm{~s}$, with the probe located on the infant's right hand. The mean $\mathrm{SaO}_{2}$ for the $5 \mathrm{~s}$ immediately preceding the partial jugular venous occlusion was taken as the value for $\mathrm{SaO}_{2}$.

At least five separate partial jugular venous occlusions were performed for each measurement, and the mean values of $\mathrm{SaO}_{2}$ and $\mathrm{SvO}_{2}$ from the five readings were used to calculate the cerebral FOE, using the following equation: $\mathrm{FOE}=\left(\mathrm{SaO}_{2}-\right.$ $\left.\mathrm{SvO}_{2}\right) / \mathrm{SaO}_{2}$. The derivation of this formula has been previously described (19).

Echocardiographic measurement of LVO. LVO was measured by echocardiography (Vingmed CFM 725 ultrasound scanner, Vingmed, Oslo, Norway) with a $7.5 \mathrm{MHz}$ probe (GE Medical Systems, Waukesha, WI, U.S.A.), a method validated in critically ill adults and an animal model of the human neonate $(20,21)$. Measurement of LVO was performed immediately after completion of cerebral measurements. Aortic diameter was measured in an M-mode parasternal long-axis view, using the trailing edge to leading edge method, which has less intraobserver variability than other methods (22). The aortic diameter was taken as the average measurement for three cycles. Aortic pulsed Doppler signals were recorded from either suprasternal or apical sites, whichever permitted best alignment of the ultrasound beam resulting in the strongest signal. The aortic flow velocity integral, which reflects average aortic red cell velocity, was assessed by measuring area under the curve of the spectral trace. LVO was calculated from aortic diameter, aortic flow velocity integral, and heart rate.

Measurement of other variables. All infants had a $\mathrm{Hb}$ measurement on each day. Blood gases and blood glucose were measured after each of the near-infrared and echocardiographic measurements. Temperature was monitored using a skin probe (Athena, S\&W Medico Teknik, Albertslund, Denmark), placed on the abdomen over the liver.

Statistics. Data were analyzed using SPSS Version 10.0.7. Changes in variables over the $3 \mathrm{~d}$ of study were analyzed using a one-way ANOVA suitable for repeated measurements within individuals. Subsequent analyses of changes between $\mathrm{d} 1$ and 2 and $\mathrm{d} 2$ and 3 were performed using the paired $t$ test with Bonferroni correction. Backwards method multiple linear regression was used to investigate which of the following variables were associated with cerebral FOE on each day: gestation, birthweight, MABP, LVO, temperature, $\mathrm{pH}$ (converted to arterial blood hydrogen ion concentration for the purpose of multiple linear regression), mean airway pressure, $\mathrm{PaCO}_{2}, \mathrm{PaO}_{2}$, arterial $\mathrm{Hb}$ concentration, and blood glucose concentration. Subsequent correlations between variables on each day were examined using the Pearson correlation coefficient. Dichotomization of LVO and cerebral FOE data were performed using $5^{\text {th }}$ or $95^{\text {th }}$ centile limits, which were defined using unpublished data provided by Dr. N, Evans, Sydney, Australia, for LVO and by our own group for cerebral FOE. Comparisons between subgroups generated in this manner were performed using the Mann-Whitney $U$ test.

\section{RESULTS}

Thirty-six infants were studied, and their descriptive details are shown in Table 1. Data are reported as mean $\pm \mathrm{SD}$, or as median (IQR) for subgroup analysis. In the following description, the term low is used to describe values below the $5^{\text {th }}$ centile, normal to describe those between the $5^{\text {th }}$ and $95^{\text {th }}$ centiles, and high to describe those above the $95^{\text {th }}$ centile.

Table 1. Descriptive details

\begin{tabular}{lc}
\hline & Mean \pm SD \\
\hline Gestation (wk) & $26 \pm 2$ \\
Birth weight $(\mathrm{g})$ & $929 \pm 250$ \\
Time of measurement d 1 (h) & $7 \pm 3$ \\
Time of measurement d 2 (h) & $29 \pm 4$ \\
Time of measurement d 3 (h) & $53 \pm 4$ \\
CRIB score* & $5(2-9)$ \\
\hline
\end{tabular}

* Data for CRIB score were not normally distributed and are therefore presented as median (IQR). 


\section{Cerebral FOE}

There were successful measurements of cerebral FOE on all $3 \mathrm{~d}$ in 25 infants. Ten infants had two successful measurements, and one infant had only one successful measurement completed. The reasons for failure of the 12 missing measurements were death before the d 3 of life (1 measurement), equipment failure ( 2 measurements), and rejection of recorded data for failure to meet preset standards, usually because of movement artifact (9 measurements).

All but four successful measurements of cerebral FOE had a corresponding successful measurement of LVO, the missing measurements being due to equipment failure. All infants with cerebral FOE measurements had continuous MABP recording.

\section{Sequential Changes between Days 1, 2, and 3}

Results for all $3 \mathrm{~d}$ are summarized in Table 2. There were significant differences across the $3 \mathrm{~d}$ of measurement in cerebral FOE $(p=0.008)$, MABP $(p=0.02)$, and LVO $(p<$ $0.0001)$. Subsequent analysis demonstrated that the significant difference lay between first and subsequent days. Cerebral FOE was significantly lower on $\mathrm{d} 2$ than on $\mathrm{d} 1(p=0.007)$. LVO was significantly higher on $\mathrm{d} 2$ than on $\mathrm{d} 1(p<0.0001)$, and although it increased again on $\mathrm{d} 3$, this change was not significant $(p=0.08)$. Although MABP increased significantly across the $3 \mathrm{~d}(p=0.02)$, the changes between $\mathrm{d} 1$ and $2(p=$ $0.1)$, and between $\mathrm{d} 2$ and $3(p=0.5)$, were not themselves significant.

Arterial $\mathrm{Hb}$ concentration decreased significantly over the $3 \mathrm{~d}$ of measurement, and the significant change occurred between $\mathrm{d} 2$ and $3(p=0.012)$. Arterial $\mathrm{pH}$ also fell significantly, the significant change occurred between $\mathrm{d} 1$ and $2(p=$ $0.018)$.

\section{The Relationships between Variables for Each Day}

Day 1. Results for d 1 are summarized in Table 2. There was a significant negative correlation between LVO and cerebral FOE (Fig. 1). There was no significant correlation between MABP and cerebral FOE (Fig. 1).

A backwards method multiple linear regression analysis was applied, using a significance level of $p<0.05$. This generated a significant model $(p=0.03)$ in which $\mathrm{LVO}$ and $\mathrm{PaCO}_{2}$ combined predicted cerebral FOE: cerebral FOE $=0.563-$ $(9 \mathrm{E}-4 \times \mathrm{LVO})-\left(2 \mathrm{E}-3 \times \mathrm{PaCO}_{2}\right)$

Of these two variables, the analysis demonstrated that only LVO was a significant independent predictor of cerebral FOE $(p=0.02)$.

The data were therefore explored further to discover the values of $\mathrm{LVO}$ and $\mathrm{PaCO}_{2}$ that influenced cerebral FOE on $\mathrm{d} 1$. Seven infants had high cerebral FOE: their median (IQR) LVO was $78(65-98) \mathrm{mL} / \mathrm{kg} / \mathrm{min}$, significantly lower $(p=0.009)$ than LVO in those infants with normal cerebral FOE, which was $130(101-167) \mathrm{mL} / \mathrm{kg} / \mathrm{min}$. Eighteen infants had low LVO: their median (IQR) cerebral FOE was 0.39 (0.34-0.47), significantly higher $(p=0.03)$ than cerebral FOE in those infants with normal LVO, which was $0.33(0.27-0.36)$.

Of the 18 infants with low LVO, cerebral FOE was high in 7 , normal in 10, and low in 1 . The seven infants with high cerebral FOE had median (IQR) $\mathrm{Paco}_{2} 37$ (28-40) $\mathrm{mm} \mathrm{Hg}$, significantly lower $(p=0.03)$ than $\mathrm{Paco}_{2}$ in the 10 infants with low LVO and normal cerebral FOE which was $43(41-46) \mathrm{mm}$ $\mathrm{Hg}$.

Day 2. Results for d 2 are summarized in Table 2. As on d 1 , infants with low LVO on $\mathrm{d} 2$ tended to have higher cerebral FOE, although this did not achieve statistical significance (Fig. 1). Also as on $d$ 1, there was no significant relationship between MABP and cerebral FOE (Fig. 1). A backwards method multiple linear regression analysis did not demonstrate any relationship between cerebral FOE and any of the measured variables, nor were any models for predicting cerebral FOE generated.

Five infants had high cerebral FOE: their median (IQR) LVO was $111(109-124) \mathrm{mL} / \mathrm{kg} / \mathrm{min}$, significantly lower $(p=$ 0.009 ) than LVO in those infants with normal cerebral FOE, which was $176(145-234) \mathrm{mL} / \mathrm{kg} / \mathrm{min}$. Seventeen infants with low LVO had median (IQR) cerebral FOE 0.30 (0.27-0.40), significantly higher $(p=0.03)$ than cerebral FOE in those infants with normal LVO, which was 0.24 (0.23-0.27).

Of the 17 infants with low LVO, cerebral FOE was high in 5 , normal in 11 , and low in 1 . The five infants with high cerebral FOE did not demonstrate any significant difference in $\mathrm{PaCO}_{2}$ when compared with those with normal cerebral FOE.

Table 2. Results summary

\begin{tabular}{|c|c|c|c|c|}
\hline & Day 1 Mean $\pm \mathrm{SD}$ & Day 2 Mean \pm SD & Day 3 Mean \pm SD & $p$ Value \\
\hline Cerebral FOE & $0.36 \pm 0.11(n=32)$ & $0.29 \pm 0.08(n=34)$ & $0.29 \pm 0.09(n=30)$ & 0.008 \\
\hline MABP $(\mathrm{mm} \mathrm{Hg})$ & $34 \pm 8(n=36)$ & $37 \pm 8(n=34)$ & $40 \pm 10(n=31)$ & 0.02 \\
\hline $\mathrm{LVO}(\mathrm{mL} / \mathrm{kg} / \mathrm{min})$ & $129.5 \pm 56.4(n=34)$ & $175.8 \pm 68.0(n=33)$ & $192.5 \pm 65.3(n=31)$ & $<0.0001$ \\
\hline $\mathrm{pH}$ & $7.38 \pm 0.09(n=36)$ & $7.33 \pm 0.08(n=34)$ & $7.31 \pm 0.04(n=31)$ & 0.009 \\
\hline $\mathrm{PaO}_{2}(\mathrm{~mm} \mathrm{Hg})$ & $56 \pm 17(n=35)$ & $61 \pm 19(n=34)$ & $61 \pm 25(n=28)$ & 0.17 \\
\hline $\mathrm{SaO}_{2}(\%)$ & $94 \pm 4(n=32)$ & $93 \pm 5(n=34)$ & $95 \pm 2(n=30)$ & 0.3 \\
\hline $\mathrm{Hb}(\mathrm{g} / \mathrm{dL})$ & $15.9 \pm 2.8(n=34)$ & $15.3 \pm 2.0(n=34)$ & $14.3 \pm 2.7(n=32)$ & 0.01 \\
\hline Temperature $\left({ }^{\circ} \mathrm{C}\right)$ & $36.5 \pm 0.7(n=33)$ & $36.7 \pm 0.5(n=30)$ & $36.6 \pm 0.5(n=28)$ & 0.6 \\
\hline
\end{tabular}

All data are presented as mean $\pm \mathrm{SD}$.

Statistical values presented have been generated by one-way ANOVA suitable for repeated measures within individuals. Details of further analyses using Bonferroni correction are documented in the text.

* Eight outlying values of blood glucose have been excluded from this data summary. 

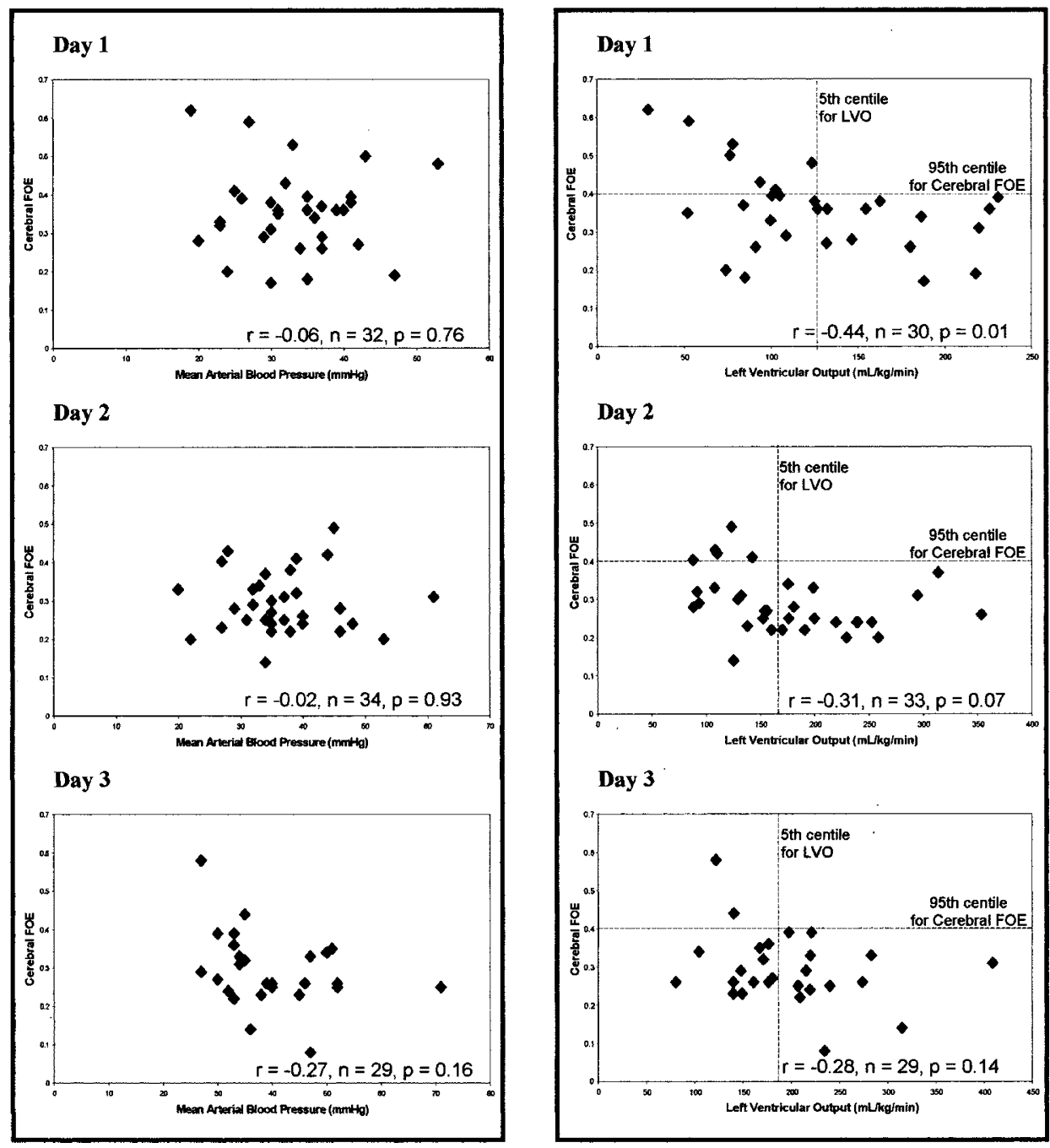

Figure 1. The relationship between cerebral FOE and MABP (left column) and cerebral FOE and LVO (right column) on d 1, 2, and 3. A significant negative correlation between cerebral FOE and LVO was present on d 1, with a similar tendency on d 2. There was no relationship between cerebral FOE and MABP on $\mathrm{d} 1,2$, or 3 .

Day 3. Results for d 3 are summarized in Table 2. The relationship that existed between $\mathrm{LVO}$ and cerebral FOE on $\mathrm{d}$ 1 was not shown to be present on subsequent days (Fig. 1). As on $\mathrm{d} 1$ and 2, there was no significant relationship between MABP and cerebral FOE (Fig. 1). A backwards method multiple linear regression analysis did not demonstrate any relationship between cerebral FOE and any of the measured variables, nor were any models for predicting cerebral FOE generated.

There were only two infants with high cerebral FOE by $\mathrm{d} 3$. These infants, with LVO of 122 and $141 \mathrm{~mL} / \mathrm{kg} / \mathrm{min}$, tended to have lower LVO $(p=0.08)$ than those infants with normal cerebral FOE, who had median LVO of $177(152-219) \mathrm{mL} /$ $\mathrm{kg} / \mathrm{min}$. Cerebral FOE in the 16 infants who had low LVO was not significantly different from that in infants with normal $\mathrm{LVO}$, in contrast to the findings on $\mathrm{d} 1$ and $\mathrm{d} 2$.

\section{DISCUSSION}

This study has shown that on the first day after birth, very low birth weight infants had increased cerebral FOE when there was hypocarbia in combination with low LVO. Descriptive analysis demonstrated an inverse relationship between LVO and cerebral FOE on d 1. MABP changes over the range that occurred in this study had no demonstrable effect on cerebral FOE.

Cerebral FOE was higher on the first day after birth than on d 2 and 3. As FOE represents the ratio of oxygen consumption to oxygen delivery, an increase may be due to increased oxygen consumption because of increased cerebral metabolic rate, decreased oxygen delivery, or both. There was no identifiable reason why the cerebral metabolic rate of any of the infants in this study might be increased, for example, none of the infants demonstrated overt seizure activity. Consequently, it is likely that increased cerebral FOE on $\mathrm{d} 1$ was a response to decreased oxygen delivery, most probably because of decreased CBF. None of the measurements in this study were made within $3 \mathrm{~h}$ of the first dose of surfactant, and all were completed before administration of the second dose, because it is known that surfactant administration has a significant effect on cerebral hemodynamics (23). No infants received any fluid 
bolus or change in inotrope administration during the measurements. Those already receiving inotropes at the time of measurement did not have a cerebral FOE that was significantly different to FOE in those that were not.

The assessment of systemic blood flow using LVO is limited in that it may reflect ductal flow. Despite this, we demonstrated a significant rise in both LVO and blood pressure over the $3 \mathrm{~d}$ after birth, as previously demonstrated by others $(24,25)$. We have shown that this was associated with a significant fall in cerebral FOE. On none of the days was there a demonstrable correlation between cerebral FOE and blood pressure. This observation is in line with other recent research that has also failed to demonstrate any association between blood pressure and $\operatorname{CBF}(6-9,26)$. There was, however, a significant negative correlation between LVO and cerebral FOE on the first day. The implication of these observations is that LVO is likely to be an important determinant of cerebral oxygen delivery, most probably by influencing CBF. This was in contrast with systemic blood pressure, which had no apparent effect.

There is little other published work concerning the relationship between LVO and cerebral oxygen delivery in newborn infants. There is, however, some evidence to support our conclusion that decreased LVO is likely to result in reduced cerebral oxygen delivery. For example, when an orogastric tube was passed in healthy preterm infants, a bradycardia of $<80$ beats per minute was associated with a significant fall in anterior cerebral artery blood flow velocity (27). Flow velocity in an individual artery, however, is not a direct measurement of global CBF. Studies of global CBF have demonstrated no significant change after therapeutic measures that altered LVO, such as dopamine or fluid bolus administration (28). Also, other research that has demonstrated a relationship between LVO and mean anterior cerebral artery blood flow velocity suggested that this relationship was mediated via changes in MABP (29).

Although we have demonstrated a negative correlation between LVO and cerebral FOE, some infants with low $\left(<5^{\text {th }}\right.$ centile) LVO were able to maintain a normal $\left(5^{\text {th }}-95^{\text {th }}\right.$ centile $)$ cerebral FOE (Fig. 1). These infants did this presumably by maintaining their $\mathrm{CBF}$ by some mechanism other than vasoconstriction in peripheral vascular beds and the maintenance of blood pressure. The most likely mechanism is through cerebral autoregulation, maintaining a stable $\mathrm{CBF}$ by vasodilatation or vasoconstriction. Consideration of the infants with low LVO revealed that those with high cerebral FOE had significantly lower $\mathrm{PaCO}_{2}$ than those with normal cerebral FOE. This suggests that, in the presence of low LVO, hypocarbia appears to be associated with an increase in cerebral FOE. This finding supports the notion that $\mathrm{PaCO}_{2}$ has a powerful effect on cerebral vascular tone and $\mathrm{CBF}$, an effect previously demonstrated in adults and newborn infants $(8,11-13,30-32)$. Our results suggest that preterm infants with low LVO and higher values of $\mathrm{PaCO}_{2}$ may be able to maintain adequate cerebral oxygen delivery, presumably by cerebral vasodilatation, to improve $\mathrm{CBF}$ and maintain a normal cerebral FOE. Infants with low LVO and low values of $\mathrm{PacO}_{2}$ would have cerebral vasoconstriction and thus reduced CBF. This would reasonably be expected to lead to reduced cerebral oxygen delivery, and cerebral FOE increased as an appropriate compensatory physiologic response. It is of interest that, in this study, infants with high cerebral FOE in the presence of low LVO included some with $\mathrm{PaCO}_{2}$ as high as $37 \mathrm{~mm} \mathrm{Hg}$, which would normally be considered to be within the normal range.

When interpreting our results it is important to consider which cerebral tissues are investigated when using nearinfrared spectroscopy. In this study, we used a differential path length factor of 3.85 , comparable to those generated previously by time of flight and second differential spectroscopy studies of the neonatal brain $(33,34)$. Thus, for an inter-optode distance of $2.5 \mathrm{~cm}$, mean depth of penetration could, at most, be only $4.8 \mathrm{~cm}$. Depth of penetration was in fact likely to be much less because of scattering, which causes the near-infrared photons to take an erratic path through the cerebral tissues. As a consequence the near-infrared photons pass largely through only the cerebral cortex. Deeper caudal structures, such as the brainstem, are therefore poorly represented by near-infrared studies such as ours.

This limitation of the technique suggests one explanation for the relationship of FOE with $\mathrm{LVO}$ and $\mathrm{PaCO}_{2}$, with no apparent change in systemic blood pressure. LVO is not the only determinant of blood pressure in the human infant (35). When LVO is low, blood pressure is maintained by vasoconstriction in the low-priority peripheral vascular beds, the purpose of which is to maintain perfusion pressure. It is possible that the cerebral hemispheres of these very immature infants are also low-priority vascular beds, in contrast to the situation in the more mature person. The implication of this notion is that when LVO is low in immature preterm babies, vasoconstriction might occur in the cerebral hemispheres, as well as in peripheral vascular beds. The purpose of such a mechanism would be to maintain CBF to more vital areas, such as the caudal areas of the brain including the brainstem.

To summarize, our findings suggest that LVO is an important determinant of cerebral oxygen delivery. As cerebral oxygen delivery decreases, cerebral FOE rises. LVO seems to have a more significant effect on cerebral oxygen delivery than MABP, at least in the range studied here, with MABP as low as $19 \mathrm{~mm} \mathrm{Hg}$ in one infant. With more severe hypotension this may not hold true. These results provide further evidence for the importance of $\mathrm{PaCO}_{2}$ as a regulator of cerebral vascular tone and consequently the adequacy of cerebral oxygen delivery. This seems to be particularly relevant in those infants with a low cardiac output state. The association between cerebral FOE and LVO, but not blood pressure, may be the result of vasoconstriction in the cerebral hemispheres as well as peripheral vascular beds, suggesting that the cerebral hemispheres may be low-priority vascular beds in the very immature human infant.

\section{REFERENCES}

1. Wood NS, Marlow N, Costeloe K, Gibson AT, Wilkinson AR 2000 Neurologic and developmental disability after extremely preterm birth. EPICure Study Group. N Engl J Med 343:378-384

2. Vohr BR, Wright LL, Dusick AM, Mele L, Verter J, Steichen JJ, Simon NP, Wilson DC, Broyles S, Bauer CR, Delaney-Black V, Yolton KA, Fleisher BE, Papile LA, Kaplan MD 2000 Neurodevelopmental and functional outcomes of extremely low 
birth weight infants in the National Institute of Child Health and Human Development Neonatal Research Network, 1993-1994. Pediatrics 105:1216-1226

3. Meek JH, Tyszczuk L, Elwell CE, Wyatt JS 1999 Low cerebral blood flow is a risk factor for severe intraventricular haemorrhage. Arch Dis Child Fetal Neonatal Ed 81:F15-F18

4. Tsuji M, Saul JP, du Plessis A, Eichenwald E, Sobh J, Crocker R, Volpe JJ 2000 Cerebral intravascular oxygenation correlates with mean arterial pressure in critically ill premature infants. Pediatrics 106:625-632

5. Cunningham S, Symon AG, Elton RA, Zhu C, McIntosh N 1999 Intra-arterial blood pressure reference ranges, death and morbidity in very low birthweight infants during the first seven days of life. Early Hum Dev 56:151-165

6. Greisen G, Trojaborg W 1987 Cerebral blood flow, $\mathrm{PaCO}_{2}$ changes, and visual evoked potentials in mechanically ventilated, preterm infants. Acta Paediatr Scand 76:394 400

7. Pellicer A, Gaya F, Stiris TA, Quero J, Cabanas F 1998 Cerebral haemodynamics in preterm infants after exposure to dexamethasone. Arch Dis Child Fetal Neonatal Ed 79:F123-F128

8. Pryds O, Andersen GE, Friis-Hansen B 1990 Cerebral blood flow reactivity in spontaneously breathing, preterm infants shortly after birth. Acta Paediatr Scand 79:391-396

9. Tyszczuk L, Meek J, Elwell C, Wyatt JS 1998 Cerebral blood flow is independent of mean arterial blood pressure in preterm infants undergoing intensive care. Pediatrics 102:337-341

10. Younkin DP, Reivich M, Jaggi JL, Obrist WD, Delivoria-Papadopoulos M 1987 The effect of hematocrit and systolic blood pressure on cerebral blood flow in newborn infants. J Cereb Blood Flow Metab 7:295-299

11. Leahy FA, Cates D, MacCallum M, Rigatto $\mathrm{H} 1980$ Effect of $\mathrm{CO}_{2}$ and $100 \% \mathrm{O}_{2}$ on cerebral blood flow in preterm infants. J Appl Physiol 48:468-472

12. Pryds O, Greisen $\mathrm{G} 1989$ Effect of $\mathrm{PaCO}_{2}$ and haemoglobin concentration on day to day variation of CBF in preterm neonates. Acta Paediatr Scand Suppl 360:33-36

13. Rahilly PM 1980 Effects of 2\% carbon dioxide, $0.5 \%$ carbon dioxide, and $100 \%$ oxygen on cranial blood flow of the human neonate. Pediatrics 66:685-689

14. Calvert SA, Hoskins EM, Fong KW, Forsyth SC 1987 Etiological factors associated with the development of periventricular leukomalacia. Acta Paediatr Scand 76:254259

15. Greisen G, Munck H, Lou H 1987 Severe hypocarbia in preterm infants and neurodevelopmental deficit. Acta Paediatr Scand 76:401-404

16. Wardle SP, Yoxall CW, Weindling AM 2000 Determinants of cerebral fractiona oxygen extraction using near infrared spectroscopy in preterm neonates. J Cereb Blood Flow Metab 20:272-279

17. Anonymous 1993 The CRIB (clinical risk index for babies) score: a tool for assessing initial neonatal risk and comparing performance of neonatal intensive care units. The International Neonatal Network. Lancet 342:193-198

18. Yoxall CW, Weindling AM, Dawani NH, Peart I 1995 Measurement of cerebra venous oxyhemoglobin saturation in children by near-infrared spectroscopy and partial jugular venous occlusion. Pediatr Res 38:319-323
19. Yoxall CW, Weindling AM 1998 Measurement of cerebral oxygen consumption in the human neonate using near infrared spectroscopy: cerebral oxygen consumption increases with advancing gestational age. Pediatr Res 44:283-290

20. Laupland KB, Bands CJ 2002 Utility of esophageal Doppler as a minimally invasive hemodynamic monitor: a review. Can J Anaesth 49:393-401

21. Kinsella JP, Morrow WR, Gerstmann DR, Taylor AF, deLemos RA 1991 Cardiac output by Doppler echocardiography in the premature baboon: comparison with radiolabeled microspheres. Pediatr Cardiol 12:92-97

22. Hudson I, Houston A, Aitchison T, Holland B, Turner T 1990 Reproducibility of measurements of cardiac output in newborn infants by Doppler ultrasound. Arch Dis Child 65:15-19

23. Lundstrom KE, Greisen G 1996 Changes in EEG, systemic circulation and blood gas parameters following two or six aliquots of porcine surfactant. Acta Paediatr 85:708 712

24. D'Souza SW, Janakova H, Minors D, Suri R, Waterhouse J, Appleton G, Ramesh C, Sims DG, Chiswick ML 1995 Blood pressure, heart rate, and skin temperature in preterm infants: associations with periventricular haemorrhage. Arch Dis Child Fetal Neonatal Ed 72:F162-F167

25. Evans N, Kluckow M, Currie A 1998 Range of echocardiographic findings in term neonates with high oxygen requirements. Arch Dis Child Fetal Neonatal Ed 78:F105F111

26. Seri I, Abbasi S, Wood DC, Gerdes JS 1998 Regional hemodynamic effects of dopamine in the sick preterm neonate. J Pediatr 133:728-734

27. Haxhija EQ, Rosegger H, Prechtl HF 1995 Vagal response to feeding tube insertion in preterm infants: has the key been found? Early Hum Dev 41:15-25

28. Lundstrom K, Pryds O, Greisen G 2000 The haemodynamic effects of dopamine and volume expansion in sick preterm infants. Early Hum Dev 57:157-163

29. van Bel F, Walther FJ 1990 Myocardial dysfunction and cerebral blood flow velocity following birth asphyxia. Acta Paediatr Scand 79:756-762

30. Aaslid R, Lindegaard KF, Sorteberg W, Nomes H 1989 Cerebral autoregulation dynamics in humans. Stroke 20:45-52

31. Pryds O, Greisen G, Lou H, Friis-Hansen B 1989 Heterogeneity of cerebral vasoreactivity in preterm infants supported by mechanical ventilation. J Pediatr 115:638645

32. Pryds O, Greisen G, Skov LL, Friis-Hansen B 1990 Carbon dioxide-related changes in cerebral blood volume and cerebral blood flow in mechanically ventilated preterm neonates: comparison of near infrared spectrophotometry and ${ }^{133}$ Xenon clearance. Pediatr Res 27:445-449

33. Cooper CE, Elwell CE, Meek JH, Matcher SJ, Wyatt JS, Cope M, Delpy DT 1996 The noninvasive measurement of absolute cerebral deoxyhemoglobin concentration and mean optical path length in the neonatal brain by second derivative near infrared spectroscopy. Pediatr Res 39:32-38

34. Wyatt JS, Cope M, Delpy DT, van der Zee, Arridge S, Edwards AD, Reynolds EO 1990 Measurement of optical path length for cerebral near-infrared spectroscopy in newborn infants. Dev Neurosci 12:140-144

35. Kluckow M, Evans N 1996 Relationship between blood pressure and cardiac output in preterm infants requiring mechanical ventilation. J Pediatr 129:506-512 